\title{
Correlation transmission of spiking neurons is boosted by synchronous input
}

\author{
Matthias Schultze-Kraft ${ }^{*}$, Markus Diesmann ${ }^{2,3,4}$, Sonja Grün ${ }^{4,5}$, Moritz Helias ${ }^{2}$ \\ From Twentieth Annual Computational Neuroscience Meeting: CNS*2011 \\ Stockholm, Sweden. 23-28 July 2011
}

Ever since the discovery of precisely timed events of cortical neurons [1], their role for information processing has been highly debated. The widespread belief that synchrony is an epiphenomenon caused by shared afferents among neurons [2] has constantly been challenged by reports observing task related modulation of synchrony, lately in primary visual cortex [3] and motor cortex [4]. More so, the recently found decorrelation in cortical networks [5] suggests that the ground state of recurrent balanced networks provides a suitable substrate on top of which synchronized events can represent information.

In this work we theoretically investigate to what extent common synaptic afferents and synchronized inputs each contribute to closely time-locked spiking activity of pairs of neurons [6]. We employ direct simulation and extend earlier analytical methods based on the diffusion approximation [7] to pulse-coupling, allowing us to introduce spiking correlations in the afferent synaptic activity. We compare situations in which the covariance in the input to a pair of model neurons is kept constant, but is realized by different proportions of common afferents and spiking synchrony. This allows us to address the question how much synchrony is caused by afferent synchronized events and how much is intrinsic to cortex due to its structure.

We find that at fixed input covariance, already weakly synchronous inputs boost the synchrony in the outgoing spiking activity compared to shared input alone (Fig. 1A), sharpening the correlation functions (Fig. 1B). In the regime of strong input synchrony we observe that the output correlation becomes even higher than the correlation in the input (cf. gray area in Fig. 1A). Recent theoretical insights [8] into the non-linear response

\footnotetext{
* Correspondence: schultze-kraft@tu-berlin.de

${ }^{1}$ Machine Learning Group, Berlin Institute of Technology, Berlin, Germany

Full list of author information is available at the end of the article
}

properties of neurons enable us to explain how such correlation transmission gain $>1$ is possible.

Partially supported by BMBF Grant 01IB001A (brain@work), the Helmholtz Alliance on Systems Biology, the Next-Generation Supercomputer Project of
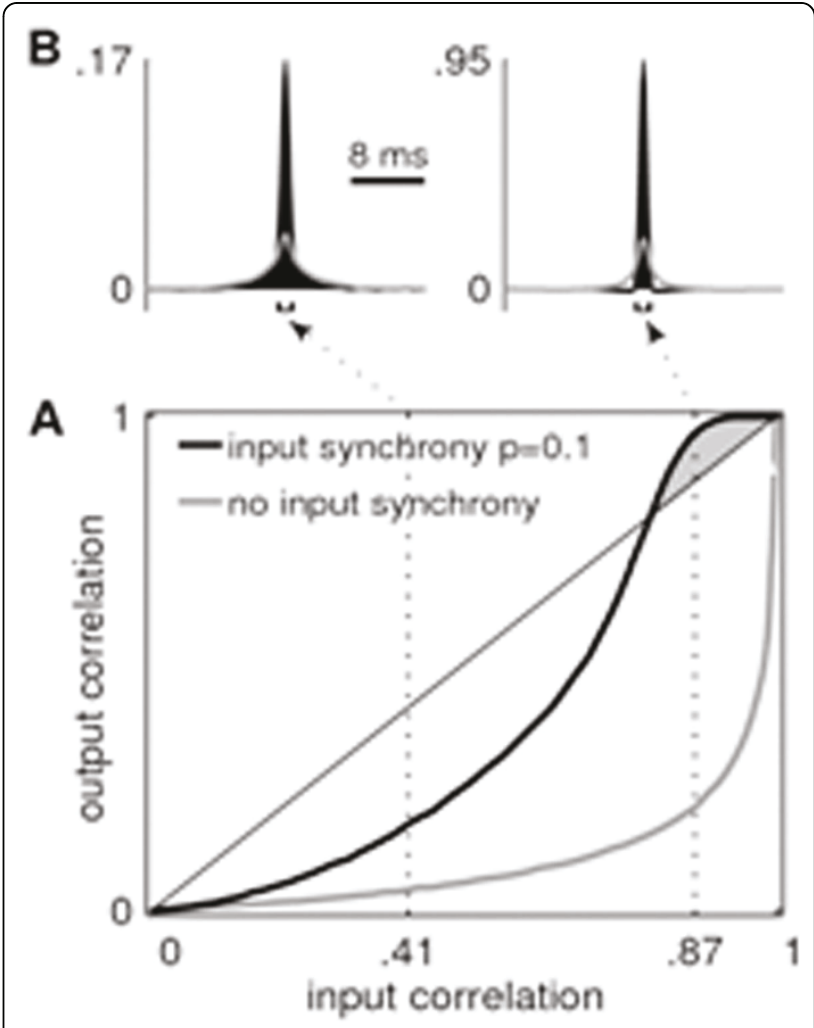

Figure 1 Correlation transmission of a pair of model neurons. A Output correlation at $1 \mathrm{~ms}$ precision as a function of input correlation. Transmission for 10 per cent pairwise synchronous input spikes in black, no input synchrony in gray. The correlation gain exceeds unity in the gray shaded area. B Time-resolved correlation functions. Same gray code as in A.

\section{C) Biomed Central}

(c) 2011 Schultze-Kraft et al; licensee BioMed Central Ltd. This is an open access article distributed under the terms of the Creative Commons Attribution License (http://creativecommons.org/licenses/by/2.0), which permits unrestricted use, distribution, and reproduction in any medium, provided the original work is properly cited. 
MEXT, EU Grant 15879 (FACETS), EU Grant 269921 (BrainScaleS). All network simulations carried out with NEST (http://www.nest-initiative.org).

\section{Author details}

${ }^{1}$ Machine Learning Group, Berlin Institute of Technology, Berlin, Germany. ${ }^{2}$ Laboratory for Computational Neurophysics, RIKEN Brain Science Institute, Wako City, Japan. ${ }^{3}$ Brain and Neural Systems Team, RIKEN Computational Science Research Program, Wako City, Japan. ${ }^{4}$ Institute of Neuroscience and Medicine (INM-6), Computational and Systems Neuroscience, Research Center Jülich, Germany. ${ }^{5}$ Laboratory for Statistical Neuroscience, RIKEN Brain

Science Institute, Wako City, Japan

Published: 18 July 2011

\section{References}

1. Abeles M: Local Cortical Circuits: An Electrophysiological Study. Springer, Berlin 1982.

2. Shadlen M, Newsome W: . J Neurosci 1998, 18(10):3870-3896.

3. Maldonado PEE, Babul CMM, Singer W, Rodriguez E, Berger D, Grün S: . J Neurophys 2008, 100:1523-1532

4. Kilavik BE, Roux S, Ponce-Alvarez A, Confais J, Grün S, Riehle A: . J Neurosci 2009, 29:12653-12663.

5. Ecker AS, Berens P, Keliris PA, Bethge M, Logothetis NK, Tolias AS: . Science 2010, 327:584-587.

6. Grün S, Diesmann M, Aertsen A: . Neural Comp 2002, 14(1):43-80

7. De La Rocha J, Doiron B, Shea-Brown E, Josic K, Reyes A: . Nature 2007, 448(7155):802-806

8. Helias M, Deger M, Rotter S, Diesmann M: . PLoS Comput Biol 2010, 6(9): e1000929.

doi:10.1186/1471-2202-12-S1-P144

Cite this article as: Schultze-Kraft et al: Correlation transmission of spiking neurons is boosted by synchronous input. BMC Neuroscience 2011 12(Suppl 1):P144.

\section{Submit your next manuscript to BioMed Central} and take full advantage of:

- Convenient online submission

- Thorough peer review

- No space constraints or color figure charges

- Immediate publication on acceptance

- Inclusion in PubMed, CAS, Scopus and Google Scholar

- Research which is freely available for redistribution

Submit your manuscript at www.biomedcentral.com/submit 